\title{
Prevalence of Generalized Joint Hypermobility and Fibromyalgia Syndrome in the Children Population of Trabzon: A Turkish Study
}

\author{
Ömer Faruk BARÇAK', Murat KARKUCAK', Erhan ÇAPKIN', Gülay KARAGÜZEL², Beril DiLBER², Süleyman Semih DEDEOĞLU³ \\ ${ }^{1}$ Department of Physical Medicine and Rehabilitation, Karadeniz Teknik University Faculty of Medicine, Trabzon, Turkey \\ ${ }^{2}$ Department of Pediatric, Karadeniz Teknik University Faculty of Medicine, Trabzon, Turkey \\ ${ }^{3}$ Department of Orthopedics and Traumatology, Bezmialem Vakıf University, Istanbul, Turkey
}

\begin{abstract}
Objective: Generalized joint hypermobility $(\mathrm{GJH})$ and fibromyalgia syndrome (FMS) are two clinical conditions that may cause common musculoskeletal pain during childhood. Our study aimed to evaluate the frequency of juvenile FMS and GJH in children aged 11-18 years in the province Trabzon as well as to evaluate the correlation between these two conditions.

Material and Methods: This cross-sectional study was conducted in 437 students aged 11-18 years who received education in Trabzon. Questionnaire forms were filled, and each student was examined. The children reported to have any disease were excluded from the study. GJH was diagnosed according to criteria of Beighton diagnosis. The presence of FMS was determined according to the 1990 American College of Rheumatology classification criteria. A total of 437 students [209 girls (52.2\%) and $228(47.8 \%)$ boys] participated in the study. The mean age was $14.3 \pm 1.7$ years for girls and $14.7 \pm 1.79$ years for boys.

Results: The frequency of GJH was found to be $9.1 \%$ and that of FMS was found to be $5.9 \%$ for children included in the study. Although significant difference was observed among the female and male participants in terms of the frequency of $G \mathrm{H}(\mathrm{p}=0.023)$, no such difference was detected in of the frequency of FMS $(p=0.065)$. A statistically significant and highly negative correlation was found between age and Beighton score $(r=-0.187, p<0.001)$. A statistically significant and highly negative correlation was found between body mass index and Beighton score $(r=-0.097, p<0.05)$. There was a correlation between success level at school and tender points. Both FMS and GJH were detected in one patient. No correlation was detected between Beighton score and tender points.

Conclusion: Similar to children in other countries, GJH and FMS are also non-rare clinical conditions in Turkey.

Keywords: Generalized joint hypermobility, fibromyalgia
\end{abstract}

\section{Introduction}

Generalized joint hypermobility $(\mathrm{G} J \mathrm{H})$ is a clinical condition that may occur alone or concomitantly with various symptoms during childhood. GJH may occur concomitantly with the findings of musculoskeletal system and especially with joint pain (1). GJH declines with age from childhood, is about three times more common in females than males, and is seen more often in Asian and African races. General population studies on children (from seven studies) show figures comparable to those on adults, with a prevalence of $10 \%-15 \%$ in boys and $20 \%-40 \%$ in girls on ages 11-17 years (2).

Fibromyalgia syndrome (FMS) is characterized by chronic and generalized musculoskeletal system pain, severe fatigue, and non-relaxing sleep. Although FMS is not identified in adults, it is often seen in children and adolescents and is defined as primary juvenile FMS (3). Features of FMS are often encountered in $\mathrm{GJH}$ patients. Evidence is inconsistent regarding whether there is a true association between the two conditions (2).

This study was accepted as an presentation at 10 ${ }^{\text {th }}$ Turkish Romatology Symposium (11-14 April 2013, Muğla, Turkey).

Address for Correspondence: Ömer Faruk Barçak, MD, Department of Physical Medicine and Rehabilitation, Karadeniz Teknik University Faculty of Medicine, Trabzon, Turkey. Phone: +90 5056151581 E-mail: dromerfaruk@yahoo.com 
In our study, we aim to show the prevalence of $\mathrm{GJH}$ and FMS in children of 11-18-year age group and to provide guiding information for rheumatologists and pediatricians who are interested in this subject. Thus, the frequency of these diseases will be determined in healthy school children and the correlation between these diseases and musculoskeletal system complaints of these children will be shown.

\section{Material and Methods}

The study was planned to determine the frequency of GJH and FMS in children aged 11-18 years who received education in the schools at the city center of Trabzon and its districts. At the first stage, Provincial Directorate for National Education was contacted and an official permission was obtained with an aim to scan the students at a rate to reflect the population. Thereafter, an application was made to the local Ethics Committee and the approval of Ethics Committee was obtained for the study.

In order to cover the students of all groups of income and education status and to consider the geographical factors, the schools to be scanned were selected from both the city center and its districts. The number of students representing the studied age group was determined to be 7075 at the schools of Trabzon city center and 9930 at district schools. It was calculated that at least 384 students should be included, with a confidence ratio of $95 \%$, the highest prevalence of $10 \%$, and a deviation of $3 \%$. For the city and each district, the students to be included in the study were distributed proportional to the student population of the city and district. The schools that were determined in the city and its districts were visited. Two questionnaire forms each and a parent consent form were provided to 437 students who were selected through random sampling. In the first form, questions were asked to obtain information on issues such as demographic characteristics, education level of parents, frequency of presentation to a health institution, family income level, success at school, consanguineous marriage among parents etc. In the second form, questions were asked to evaluate the musculoskeletal system complaints. Parent consent forms, which were provided together with the forms, were distributed to the students. One week later, the schools were revisited, questionnaire forms and permission documents were evaluated, and detailed information was obtained regarding the examination to be performed in 437 children without any chronic disease and the children from whom a parent consent form needed to be obtained. It was explained that the examination is a short, harmless, and painless procedure.

During the examination stage, an appropriate enclosed place was initially determined at school. Thereafter, the examination of the students determined under the supervision of a teacher assigned by the school administration was performed by a physiotherapist and a pediatrician. The criteria of Beighton were used for the diagnosis of hypermobility, and the criteria defined by American College of Rheumatology (ACR) in 1990 were used for the diagnosis of fibromyalgia $(4,5)$. Scores of 5 and above in the criteria of Beighton were evaluated as $\mathrm{GJH}$. The range of motion was measured by a goniometer (Baseline, Nexgen, Quebec, Canada).

\section{Statistical Analysis}

Suitability of the data obtained with measurement was examined using the Kolmogorow-Smirnov test. For the comparison of measurement data of two groups, the Student t-test was used for data suitable for normal distribution and the Mann-Whitney $U$ test was used for data not suitable for normal distribution. For the comparison of multiple groups, ANOVA (post-hoc Bonferroni) was used for data suitable for normal distribution. The Chi-square test was used to compare qualitative data. During the review of the correlation analysis, Pearson correlation analysis was used for data suitable for normal distribution and Spearman correlation analysis was used for data not suitable for normal distribution. The data obtained with measurement was indicated as the arithmetical mean \pm standard deviation and the data obtained with counting was indicated as number (\%). A p-value of $<0.05$ was assumed to be the significance level.

\section{Results}

A total of 437 students, 209 of whom were girls (52.2\%) and $228(47.8 \%)$ of whom were boys, participated in the

Table 1. Distribution of participants as per sociodemographic characteristics

\begin{tabular}{|c|c|c|}
\hline & $\begin{array}{c}\text { Girl } \\
\text { Mean } \pm \text { SD }\end{array}$ & $\begin{array}{c}\text { Boy } \\
\text { Mean } \pm S D\end{array}$ \\
\hline Age (years) & $14.3 \pm 1.7$ & $14.7 \pm 1.7$ \\
\hline BMI $\left(\mathrm{kg} / \mathrm{m}^{2}\right)$ & $21.2 \pm 3.5$ & $21.6 \pm 3.8$ \\
\hline Sociodemographic characteristics & $\mathbf{n}$ & $\%$ \\
\hline \multicolumn{3}{|l|}{ Gender } \\
\hline Girl & 209 & 47.8 \\
\hline Boy & 228 & 52.2 \\
\hline \multicolumn{3}{|l|}{ Location } \\
\hline City center & 172 & 36 \\
\hline District center & 265 & 54 \\
\hline \multicolumn{3}{|l|}{$\begin{array}{l}\text { Presentation to health institutions } \\
\text { (within the last year) }\end{array}$} \\
\hline $0-3$ times & 320 & 73.2 \\
\hline $3-5$ & 92 & 21.1 \\
\hline Above 5 & 25 & 5.7 \\
\hline \multicolumn{3}{|l|}{ Joint pain } \\
\hline Yes & 160 & 36.6 \\
\hline \multicolumn{3}{|l|}{ Frequency of physical activity } \\
\hline None & 67 & 15.4 \\
\hline 1 day a month & 60 & 13.5 \\
\hline 1 day a week & 121 & 27.8 \\
\hline 2-3 days a week & 115 & 26.4 \\
\hline 1 day to $2 \mathrm{~h}$ a day & 74 & 16.9 \\
\hline Total & 437 & 100 \\
\hline
\end{tabular}

BMI: body mass index

Table 2. Frequency of generalized joint hypermobility and fibromyalgia syndrome in the participants

\begin{tabular}{lcccc} 
& Girl n (\%) & Boy n (\%) & Total n (\%) & p \\
\hline $\begin{array}{l}\text { Generalized joint } \\
\text { hypermobility }\end{array}$ & $26(12.4)$ & $14(6.1)$ & $40(9.1)$ & 0.023 \\
$\begin{array}{l}\text { Fibromyalgia } \\
\text { syndrome }\end{array}$ & $17(8.1)$ & $9(3.9)$ & $26(5.9)$ & 0.065 \\
& & & &
\end{tabular}




\begin{tabular}{|c|c|c|c|c|c|}
\hline & Age & Tender point & $\begin{array}{c}\text { Frequency of } \\
\text { performing exercise }\end{array}$ & BMI & Beighton score \\
\hline Tender point & -0.30 & 1 & -0.054 & -0.016 & 0.048 \\
\hline $\mathrm{BMI}$ & $0.300^{* *}$ & -0.016 & 0.006 & 1 & $-0.097^{\star}$ \\
\hline Beighton score & $-0.187^{* *}$ & 0.048 & -0.040 & $-0.097^{*}$ & 1 \\
\hline
\end{tabular}

${ }^{*} \mathrm{p}<0.05 ;{ }^{* *} \mathrm{p}<0.001$. BMl: body mass index

Table 4. Review of the correlation between participants' success level at school, Beighton score, and frequency of sensitive point

\begin{tabular}{lcccc} 
& $\begin{array}{c}\text { Very good } \\
\text { Mean } \pm \text { SD }\end{array}$ & $\begin{array}{c}\text { Good } \\
\text { Mean } \pm \text { SD }\end{array}$ & $\begin{array}{c}\text { Pass } \\
\text { Mean } \pm \text { SD }\end{array}$ & p \\
\hline Tender point & $2.6 \pm 4.1$ & $1.6 \pm 3.2$ & $1.5 \pm 3.1$ & 0.033 \\
Beighton score & $1.8 \pm 1.8$ & $1.4 \pm 1.7$ & $1.1 \pm 1.6$ & 0.062
\end{tabular}

study. The subjects' mean age was $14.3 \pm 1.7$ years for girls and $14.7 \pm 1.79$ years for boys. The body mass index (BMI) of the girls was $21.2 \pm 3.5 \mathrm{~kg} / \mathrm{m}^{2}$ and of the boys was $21.6 \pm 3.8$ $\mathrm{kg} / \mathrm{m}^{2}$. One hundred seventy-two (36\%) students participated from the city center and 265 (54\%) from the district centers. The presentations of the students to the health institution for any complaint in 1 year were examined: 320 students $(73.2 \%)$ presented to the health institution 0-3 times, $92(21.1 \%)$ presented 3-5 times, and 25 (5.7\%) presented more than 5 times. The students participating in the study were questioned in terms of presence and the time of previous joint complaints. Accordingly, the number of participants who previously had a joint-related complaint was found to be $160(36.6 \%), 44(10.1 \%)$ of whom had a joint-related complaint 3 months previously, 21 (4.9\%) had it 6 months ago, $40(9.1 \%)$ had it 1 year ago, and $55(12.5 \%)$ had it more than 1 year previously. The distribution of participants as per several sociodemographic characteristics is provided in Table 1.

Upon review of the frequency of GJH and FMS, the frequency of $\mathrm{GJH}$ was $9.1 \%$ and of FMS was $5.9 \%$. Twentysix of 40 participants in whom GJH was detected and had a Beighton score of 5 and above consisted of girls (12.4\% of the girls). The number of male participants in whom GJH was detected was found to be 14 (6.1\% of the boys). Upon review of frequency of FMS, the total number of tender points in 26 participants was 11 and above as per the ACR criteria, $17(8.1 \%)$ of them consistee of female participants and nine of them (3.9\%) of male participants. There was a significant difference between female and male participants in terms of the frequency of $G) H(p=0.023)$. No significant difference was found between female and male participants in terms of the frequency of FMS $(p=0.065)$. One patient met the diagnostic criteria of both FMS and GJH. When the cut-off value for $\mathrm{GJH}$ was 4 and above, the prevalence of the disease was found to be $13.9 \%$. In such a case, only one patient met the diagnostic criteria of both diseases. The participants' frequency of $\mathrm{GJH}$ and FMS is provided in Table 2.

On the evaluation of tender points, the tender point value was $1.5 \pm 3.2$ in the group with no joint complaint and was $2.2 \pm 3.6$ in the group with joint pain. Statistical significance was detected between both groups $(p=0.005)$. Upon dividing the students as "present" and "absent" as per previous trauma history, no statistically significant difference was detected in both groups in terms of Beighton score and frequency of tender points.

The correlation between age, number of tender points, frequency of performing exercise, BMI, and Beighton score of participants was studied. A statistically significant and poor correlation was observed between age and $\mathrm{BMI}(\mathrm{r}=0.300, \mathrm{p}<0.001)$. A statistically significant and highly negative correlation was found between age and Beighton score $(r=-0.187, p<0.001)$. A statistically significant and highly negative correlation was found between BMI and Beighton score $(r=-0.097, p<0.05)$. The correlation between age, tender points, frequency of performing exercise, BMI, and Beighton score of participants' is shown in Table 3 ( $r$, coefficient of correlation). No correlation was detected between Beighton score and the number of tender points.

The students were divided into three groups, "very good," "good," and "pass," according to per the success level at school. The corresponding number of tender points in the three groups was $2.6 \pm 4.1,1.6 \pm 3.2$, and $1.5 \pm 3.1$. Accordingly, there was a statistically significant difference between the number of tender points and the success level at school $(p=0.033)$. There was no statistical significance between the success level at school and Beighton score $(p=0.062)$. The correlation between participants' success level at school, Beighton score, and tender point is shown in Table 4. 
Table 5. Frequency of hypermobility in various populations

\begin{tabular}{|c|c|c|c|c|}
\hline Population & Age range & Number of cases (n) & Hypermobility (\%) & Hypermobility (\%) Girl/Boy \\
\hline *Spanish study (15) & $4-14$ & 222 & $55(71 \%,<8$ y) & \\
\hline **Brazilian study (16) & $4-7$ & 1120 & 64.6 & \\
\hline *Icelandic study (17) & 12 & 267 & 26.7 & $40.5 / 12.9$ \\
\hline *Egyptian study (18) & $6-12$ & 997 & 16 & \\
\hline${ }^{* \star \star}$ Our study & $11-18$ & 437 & 9.1 & $12.4 / 6.1$ \\
\hline
\end{tabular}

*Beighton limit value $\geq 4 / 9$; **Beighton limit value $\geq 3 / 9$; ***Beighton limit value $\geq 5 / 9$

Table 6. Studies that examine the correlation between joint pain and hypermobility

\begin{tabular}{lccc} 
& & \multicolumn{2}{c}{ Patients with joint pain } \\
\cline { 3 - 4 } Study & $\begin{array}{c}\text { Patient population, } \\
\text { Age range (year) }\end{array}$ & $\begin{array}{c}\text { Hypermobile } \\
\mathbf{n}(\%)\end{array}$ & $\begin{array}{c}\text { Non-hypermobile } \\
\mathbf{n}(\%)\end{array}$ \\
\hline${ }^{*}$ Gedalia (13) & Students, 6-14 & $53(40)$ & $52(17)$ \\
*El-Garf (18) & Students, 6-15 & $161(16)$ & $836(10)$ \\
**Seçkin (12) & Students & $101(17)$ & $760(15)$ \\
${ }^{*}$ Diaz (23) & Male soldiers, 17 & $223(10)$ & $452(4)$ \\
*Larsson (10) & Musician 18-68 & $198(5)$ & $462(18)$ \\
**Al-Rawi (24) & Students, 20-24 & $528(13)$ & $1246(12)$ \\
\hline${ }^{*} \mathrm{p}<0.05 ;{ }^{* *} \mathrm{p}>0.05$ & & &
\end{tabular}

\section{Discussion}

$\mathrm{GJH}$ and FMS are the diseases that may cause musculoskeletal system pain during childhood. In our study, we investigated the frequency of $\mathrm{GJH}$ and FMS in our region and found the prevalence of $\mathrm{GJH}$ as $9.1 \%$ and of FMS as $5.9 \%$.

$\mathrm{GJH}$ is a clinical syndrome that is characterized by the fact that the joints have a range of motion above normal levels without a correlation with any systemic rheumatic disease. The specific definition of GJH was shown by Kirk et al. (6) in 1967.

FMS is a non-joint rheumatic disease characterized with generalized body pain, for which the etiology is not determined, sensitivity in certain anatomic regions, decreased pain threshold, sleep disorders, fatigue, and often with psychological problems. Fibromyalgia is considered to be common in children. However, it is quite difficult to determine the symptoms in children and the prevalence of the disease in children is not well understood. Clinical properties of juvenile FMS resemble those of adult FMS. It was first reported by Yunus et al. (7) in 1985. It often starts at the age of 13-15, and girls are affected at a higher rate. $\mathrm{GJH}$ and FMS are also common in children, often cause musculoskeletal system pain, and are not considered at the first glance. In our study, we tried to determine the prevalence of GJH and FMS in children of 11-18-year age group and to provide guiding in- formation for clinicians. Thus, the frequency of this disease will be determined in healthy school children, and the correlation between these diseases and musculoskeletal system complaints of these children will be shown.

Although $\mathrm{GJH}$ is found in nearly $5-15 \%$ of healthy individuals in the society without any symptoms, it may result in complaints of chronic pain in some $(8,9)$. Previous studies have shown that hypermobility decreases with increasing age $(10,11)$. It was reported that the prevalence of hypermobility is between 10 and $25 \%$ in children (12). On the basis of the differences in the scoring system and the fact that the diagnostic criteria used to define the disease have multiple choice, it was observed that the hypermobility showed a wide range such as 3\%-43\% $(13,14)$. The prevalence of $\mathrm{GJH}$ in children of various populations is shown in Table 5 (15-19).

In Turkey, 861 children between ages 13-19 years of age were examined by Seçkin et al. (12); GJH was detected in 101 of these children (11.7\%). The prevalence of $\mathrm{GJH}$ was found to be $7.2 \%$ in boys and $16.2 \%$ in girls. In addition, in another study performed by Yıldırım et al. (20) in Turkey, a total of 857 children (428 girls, 429 boys) with a mean age of $10.5 \pm 2.4$ years (the limit is 6-16 years) were examined. In 118 of 857 children (13\%), GJH was detected in 85 girls (19.9\%) and 33 boys (7.7\%). In this study, children with a limit value above 6 points in the diagnostic criteria of Beighton were considered as having $\mathrm{GJ} \mathrm{H}$. In our study, the prevalence of $\mathrm{GJH}$ was $9.1 \%$. The value of $9.1 \%$ compared with $11.7 \%$ in the study by Seçkin et al. (12) may result from the use of a limit value of 4 points in the Beighton scoring system.

There is no internationally accepted consensus regarding the threshold value among the authors who use Beighton criteria. Although the threshold value is considered to be 4 in the Beighton scoring system $(8,14)$, Dolan et al. (21) considered the values of 2 and above as hypermobile in the Beighton scoring system in their study. In addition, Mikkelsson et al. (22) suggested that the threshold value of Beighton score should be 6 and above in the diagnosis of hypermobility. As it can be seen, this diversity causes different results in the calculations of the incidence and prevalence.

One of the most common complaints during childhood is musculoskeletal system pain. As shown by various studies, one 
of the significant reasons for extremity pain is $\mathrm{GJH}(10,12,13)$. In our study, no significant correlation was found between $\mathrm{GJH}$ and joint pain. The studies on the correlation between joint pain and $\mathrm{GJH}$ are summarized in Table $6(23,24)$.

In Turkey, no study was performed on FMS prevalence in healthy children. In our study, FMS was detected in 26 of 437 (5.9\%) students, 17 (3.9\%) of them were female students and 9 (2\%) were male students.

Upon review of the difference in the prevalence of FMS between genders, female participants were predominant in majority of the studies on adults $(25,26)$. In these studies, statistically significant difference was detected in terms of FMS between women and men. In our study, the prevalence of FMS was found to be $8.1 \%$ in girls and $3.9 \%$ in men. Also, as the success level of children at school increased, the number of tender points increased as well. The fact that that the children are subject to exam marathons at a very early age as well as the intense physical-psychological stress factors they experience may be suggested as an assumption regarding this issue.

There are publications that examined the correlation between FMS and GJH in the literature. In a study on adult women by Şendur et al. (27) in Turkey, hypermobility was detected at a ratio of $46.6 \%$ of women with FMS compared with the ratio of $28 \%$ in the control group. Thus, GJH was found to be statistically significant in the FMS group. In a study conducted in 338 children at ages 9-15 years by Gedalia et al. (13), GJH was detected in 17 of 21 children (81\%) with FMS, and FMS was detected in 17 of 43 (39\%) children with GJH. Also, in this study, a statistically significant difference was found between GJH and FMS.

In a study that investigated patients who presented with the complaint of generalized pain at the rheumatology clinic, the following were reported: the hypermobility ratio was equal in the control group and the patients diagnosed with FMS, FMS and GJH are two different and uncorrelated diseases, and the $\mathrm{GJH}$ ratio was higher in patients who did not fully meet the ACR criteria although they had a complaint of generalized pain (28).

In patients with FMS, majority of the tender points are localized in musculotendinous junctions. Therefore, sensitivity may also be detected in tender points in patients with $\mathrm{GJH}$. Patients with $\mathrm{GJH}$ may be misdiagnosed because of detecting sleep disorder and sensitivity in tender points as well as generalized or localized muscle and joint complaints (29). Studies supporting this opinion are available in the literature. Hudson et al. (8) detected that some of the patients with GJH who presented at the rheumatology clinic were diagnosed with soft tissue rheumatism. Biro et al. (9) reported that they detected generalized musculoskeletal system pain in $6 \%$ of the children with $\mathrm{GJH}$ who presented at the pediatric clinic. However, in our study, no significant correlation was found between $\mathrm{GJH}$ and FMS.

On average, children and adolescents have a higher ratio of range of motion compared to adults. As also confirmed by our study, this ratio decreases with increasing age. In time, this decrease, whether physiologically or pathologically, varies with individuals and population. It is clear that it is not certain whether the individuals who are considered hypermobile by various scoring systems would definitely have a history of musculoskeletal system problems or would develop such problems in their lifetime.

Consequently, similar to other countries, joint hypermobility is a common clinical picture during childhood in Turkey as well. Joint hypermobility in Turkish children is more common in girls, and its frequency decreases with increasing age. In majority of the previous studies, it was suggested that when physicians make a differential diagnosis for complaints of musculoskeletal system and, especially, of joint pain, they must also consider joint hypermobility. Because no correlation was found between joint pain and $\mathrm{GJ} \mathrm{H}$ in our study, before mentioning $\mathrm{GJ} \mathrm{H}$ as a reason for pain in children, a differential diagnosis of other diseases that may cause joint pain must be made. In addition, the FMS prevalence of $5.9 \%$ in our study indicates that FMS is quite a common disease in children as well.

\section{Conclusion}

While reviewing the complaints of musculoskeletal system in children, FMS must be considered in the differential diagnosis. Similar to children in other countries, GJH and FMS are also nonrare clinical conditions in Turkey.

Ethics Committee Approval: Ethics committee approval was received for this study from the ethics committee of Karadeniz Technical University of Medicine Ethics Committee.

Informed Consent: Informed consent was obtained from each participant.

Author contributions: Concept - Ö.F.B., M.K.; Design - Ö.F.B., M.K.; Supervision - G.K., B.D.; Resource - Ö.F.B., B.D.; Materials - Ö.F.B., M.K., B.D.; Data Collection and/or Processing - Ö.F.B., B.D.; Analysis and/or Interpretation - M.K., E.Ç., G.K.; Literature Search - M.K., E.Ç., S.S.D.; Writing - M.K., E.Ç.; Critical Reviews - Ö.F.B., M.K., E.Ç., G.K., B.D., S.S.D.

Conflict of Interest: No conflict of interest was declared by the authors.

Financial Disclosure: The authors declared that this study has received no financial support.

\section{References}

1. Grahame R. Hypermobility syndrome. In: Klippel JH, Dieppe PA, eds. Rheumatology. London: Mosby- Year Book Europe Limited Lynton House, 1994: 5.18.1-5.18.

2. Hakim AJ, Grahame R. Joint hypermobility. Best Pract Res Clin Rheumatol 2003;1 7:989-1004. [CrossRef]

3. Goldenberg DL. Fibromyalgia. In:Klippel JH, Dieppe PA, Eds. Rheumatology, 2nd Ed, London: Mosby, 1998;4:15.1-2.

4. Beighton P, Grahame R, Bird H. Hypermobility of Joints. New York, NY:Springer- Verlag; 1983:125-49. [CrossRef]

5. Wolfe F, Smythe HA, Yunus MB, Bennett RM, Bombardier C, Goldenberg DL, et al. The American College of Rheumatology 1990 
Criteria for the Classification of Fibromyalgia. Report of the Multicenter Criteria Committee. Arthritis Rheum 1990;33:160-72. [CrossRef]

6. Kirk JA, Ansell BM, Bywaters EG. The hypermobility syndrome. Musculoskeletal complaints associated with generalized joint hypermobility. Ann Rheum Dis 1967;26:419-25. [CrossRef]

7. Yunus MB, Masi AT. Juvenile primary fibromyalgia syndrome. A clinical study of thirty-three patients and matched normal controls. Arthritis Rheum 1985;28:138-45. [CrossRef]

8. Hudson N, Starr MR, Esdaile JM, Fitzcharles MA. Diagnostic associations with hypermobility in rheumatology patients. $\mathrm{Br}$ J Rheumatol 1995;34:1157-61. [CrossRef]

9. Biro F, Gewanter HL, Baum J. The hypermobility syndrome. Pediatrics 1983;72:701-6.

10. Larsson LG, Baum J, Mudholkar GS. Hypermobility: Features and differential incidence between the sexes. Arthritis Rheum 1987;30:1426-30. [CrossRef]

11. Russek L. Hypermobility syndrome. Physical Therapy 1999;79:591-7.

12. Seçkin U, Sonel B, Yilmaz O, Yagci I, Bodur H, Arasil T. The prevalenceof joint hypermobility among high school students. Rheumatol Int 2005;25:260-3. [CrossRef]

13. Gedalia A, Press ], Klein M, Buskila D. Joint hypermobility and fibromyalgia in schoolchildren. Ann Rheum Dis 1993;52:494-6. [CrossRef]

14. Birrell FN, Adebajo A, Hazleman BL, Silman AJ. High prevalence of joint laxity in West Africans. Br J Rheumatol 1994;33:56-9. [CrossRef]

15. De Inocencio Arocena J, Ocana Casas I, Benito Ortiz L. Joint hypermobility: prevalence and relationship with musculoskeletal pain. An Pediatr (Barc) 2004;61:162-6. [CrossRef]

16. Lamari NM, Chueire AG, Cordeiro JA. Analysis of joint mobility patterns among preschool children. Sao Paulo Med J 2005;123:119-23. [CrossRef]

17. Van der Giessen LJ, Liekens D, Rutgers KJ, Hartman A, Mulder PG, Oranje AP. Validation of Beighton score and prevalence of connective tissue signs in 773 Dutch children. J Rheumatol 2001;28:2726-30.
18. El-Garf AK, Mahmoud GA, Mahgoub EH. Hypermobility among Egyptian children: prevalence and features. J Rheumatol 1998;25:1003-5.

19. Gedalia A, Press J, Buskila D. Diffuse musculoskeletal pain syndromes in pediatric practice. J Clin Rheumatol 1996;2:325-30. [CrossRef]

20. Yıldırım Y, Yılmaz S, Ayhan E, Saygı S, Yanaral F, Zubarioğlu UA, et al. The frecuency of joint hypermobility in healty school children. Türk Pediatri Arşivi 2005;40:83-6.

21. Dolan AL, Hart DJ, Doyle DV, Grahame R, Spector TD. The relationship of joint hypermobility, bone mineral density, and osteoarthritis in the general population: the Chingford study. J Rheumatol 2003;30:799803.

22. Mikkelsson M, Sourander A, Piha J, Salminen JJ. Psychiatric symptoms in preadolescents with musculoskeletal pain and fibromyalgia. Pediatrics 1997;100:220-7. [CrossRef]

23. Diaz M, Estevez E, Guijo P. Joint hyperlaxity and musculoligamentous lesions: Study of a population of homogeneous age, sex and physical exertion. Br J Rheumatol 1993;32:1053-6. [CrossRef]

24. Al-Rawi ZS, Al-Aszawi AJ, Al-Chalabi T. Joint mobility among university students in Iraq. Br J Rheumatol 1985;24:326-31. [CrossRef]

25. McNally JD, Matheson DA, Bakowsky VS. The epidemiology of self-reported fibromyalgia in Canada. Chronic Dis Can 2006;27:9-16.

26. Carmona L, Ballina J, Gabriel R, Laffon A. The burden of musculoskeletal diseases in the general population of Spain: Results from a national survey. Ann Rheum Dis 2001;60:1040-5. [CrossRef]

27. Sendur OF, Gurer G, Bozbas GT. The frequency of hypermobility and its relationship with clinical findings of fibromyalgia patients. Clin Rheumatol 2007;26:485-7. [CrossRef]

28. Karaaslan Y, Haznedaroğlu S, Öztürk M. Joint hypermobility and primary fibromyalgia. J Rheumatol 2000;27:1774-6.

29. Goldman JA. Fibromyalgia and hypermobility. J Rheumatol 2001;28:920-1. 